\title{
THE ENVIRONMENTAL IMPLICATIONS OF LAND USE AND LAND COVER CHANGES AROUND A MINED AREA AT MADAYIPARA IN KANNUR DISTRICT, KERALA STATE, INDIA
}

\author{
${ }^{1 *}$ MA Mohammed Aslam, ${ }^{2}$ Lalitha M. and ${ }^{3}$ B. Mahalingam \\ ${ }^{1}$ Department of Geology, Central University of Karnataka, Kalaburagi (Karnataka), India \\ ${ }^{2}$ Department of Geology, Government College, Kasaragod (Kerala), India \\ ${ }^{3}$ Department of Geography, Central University of Karnataka, Kalaburagi, (Karnataka), India \\ Email:maslam.in@gmail.com
}

\begin{abstract}
The land use and land cover (LULC) pattern of an area is determined by natural process and human utilization over time and space. Human interventions of mining activities and its surrounding area cause changes in landcover and land use pattern. The land use and land cover changes in Madayipara area of Kannur district, Kerala State, India, which contains the area of clay mining has been studied. The spatial distribution and temporal changes of different land use and land cover classes were attempted. Landsat-5 Thematic Mapper and Sentinel-2 satellite imageries were used to study the changes in vegetation pattern, land modification and changes in water bodies. Distinct increase in area of mining area was not visible, as the excavation was mostly happened vertically in the same areal coverage. This study is helpful in the better management of environmental sustainability.
\end{abstract}

Key words: Mining Area; Land cover; Land use; Environment

\section{Introduction}

Land cover indicates the physical appearance of the land surface, such as grasslands, forest, bare soil, exposed rock, developed land. Whereas, land use indicates the purpose for which the land is used, like residential, commercial, agricultural, managed forest and rangeland. Together land use and land cover information suggest specific characteristics of the land surface, such as imperviousness, solar reflectivity, vegetation type and building morphology, this can be incorporated into environmental models as distributed or bulk parameterizations (Burian et al., 2002). Since the land is changing by natural process and human interferences, the information on land use and land cover is important for planning and management of resources needed for human welfare (Opeyemi, 2006). Remote sensing data plays a major role for mapping earth surface features (Mohammed-Aslam et. al, 2006; Reis, 2008; Mohammed-Aslam et. al, 2010). It is used as a powerful tool to monitor the Earth's surface, particularly in producing land use and land cover (LULC) classifications (Christoph et al., 2016). Remotely sensed data are useful for the mapping of land use and land cover (Jeffrey and Jonathan, 2003). The easy availability of coarse spatial resolution satellites is useful in the land use and land cover classification for environmental studies. The Sentinel-2 satellite by ESA (European Space Agency) is ideal for classification of land use and land cover as it is having 13 high quality radiometric bands (Borràs, et al., 2017). Sentinel-2 is a satellite owned by ESA, provides long-range of electromagnetic information with wide coverage and good spatial and temporal resolution (Zheng et al., 2017). The recent studies using Sentinel satellites (Gordana, 2018; Rao and Kumar, 2017; Steinhausen et al., 2018; Nicola et al., 2017) for land use and land cover mapping have demonstrated that Sentinel satellite imageries are highly suitable for land use and land cover mapping. Several land use and land cover studies were conducted using Landsat 5 satellite and it was found as suitable data for land use and land cover analysis study. The study conducted by Abdel Rahman in 1996 to map the LULC using Landsat 5 for East Nile Delta, Egypt, showed the capability of Landsat 5 data for land use and land cover classification. Landsat 5 Thematic Mapper for the year 2000 and Sentinel data for 2017 respectively were used in this study. An attempt has been made to map the land use and land cover of present study area using Sentinel-2 and Landsat satellite images.

Since the land use and land cover classification provides the base for many applications, the selection of appropriate classification algorithm and accuracy is very important (Ustuner et al., 2015) in this process. Supervised, unsupervised, hybrid classification, maximum 
likelihood classifier, artificial neural network classifier, object-based image analysis and supportive vector machine are the techniques used for classification purposes (Abburu and Golla, 2015). Among the existing satellite image classification techniques, Supportive Vector Machine (SVM) classification was highly used in recent time due to optimal separating hyperplane between classes (Bahari et al., 2014). SVM is one of the best superior machine learning algorithms for classification of high dimensional data (Huang et al., 2002). This algorithm was widely adopted for remote sensing data analysis. It is a nonparametric supervised classification algorithm that is proved to be a robust method used for pattern recognition (Sukawattanavijit and Chen, 2017). The use of SVM algorithm is getting increased attraction due to the advantages it possesses (Martins et al., 2016). The result obtained from SVM classification is relatively better than maximum likelihood classifier (Taati et al., 2014). Therefore, keeping the advantages and accuracy of results, the SVM classification method has been followed in this study.

\section{Methodology}

Land use and land cover of study area was generated using Sentinel-2 and Landsat -5 satellite imageries, acquired on $28^{\text {th }}$ December 2017 and 21 January 2000 respectively. The sentinel image was downloaded from "scihub.copernicus.eu" and Landsat-5 image was downloaded from "USGS Glovis" for free of cost. The Landsat-5 satellite bands 1, 2, 3, 4, 5 and 7 are having same spatial resolution of $30 \mathrm{~m}$ were considered for the classification LULC of study area for the year 2000. The Sentinel satellites bands 2, 3, 4 and 8 are having same spatial resolution of $10 \mathrm{~m}$ were considered for the classification LULC for the year 2017. The downloaded satellite imageries were preprocessed before the classification. The land use and land cover identification were carried out using Supportive Vector Machine (SVM) classifier technique in ArcGIS environment. Totally five classes were chosen for classification as the study area is predominately covered by it, such as barren land, built up land, mining land, vegetation and waterbodies. To classify the satellite imagery using SVM technique it is necessary to create a signature file, hence, 75 samples for vegetation, 50 samples for built up land, 40 samples for barren land, 15 samples for waterbodies and 10 samples for mining land were selected on satellite imagery, using the representative pixels. These signature files were used as input data to classify the entire imageries. The result of classification was subjected to accuracy assessment to understand the precision of classified classes. Ground verification is conducted with the help of Global Positioning System (GPS) to determine the accuracy of classification result. The verified ground information is compared with the classification result of satellite image and error matrices are generated (Paliwal and Katiyar, 2015; Kim, 2016). The error matrices and Kappa coefficient are the standard way of assessing accuracy of land use and land cover classification, generated by comparing classified land use and land cover samples with the information collected in the field using GPS (Adam et al, 2013).

Therefore, in order to access the accuracy of land use and land cover classification of this study, a total of 150 samples were chosen which consist 20 samples for barren land, 40 samples for built up land, 5 samples for mining land, 80 samples for vegetation and 5 samples for waterbodies respectively. The latitude and longitude of the selected samples were loaded in handheld GPS and field verification was carried out to compare the classification result with real world situation. The comparison of collected satellite image information and ground information was analyzed using error matrix. The error matrix is an array of information where classified classes are shown. The information in the columns was indicated by reference data or ground truth while the information in the rows was indicated by mapped classes of satellite images. It has numbers as the quantity of sample unit for any particular quantity arranged in rows and columns i.e. square matrix where columns represent the referencing data while row represents the classification data. It is useful in calculating the parameters like the producer's accuracy, user's accuracy, overall accuracy and the kappa statistics (Nain and Kumar, 2016).

The error matrix and kappa coefficient are predominantly used for land use and land cover classification derived from satellite image for accuracy determination, which is based on the comparison of ground truth against classified result by classifier. (Upadhyay et al., 2015). Table 1 shows the error matrix of the study area. 
Table 01: Error Matric of the Classified Image of the Study Area

\begin{tabular}{|c|c|c|c|c|c|c|c|}
\hline Classes & $\begin{array}{c}\text { Barren } \\
\text { Land }\end{array}$ & $\begin{array}{c}\text { Built Up } \\
\text { Land }\end{array}$ & $\begin{array}{l}\text { Mining } \\
\text { Land }\end{array}$ & Vegetation & $\begin{array}{c}\text { Water } \\
\text { bodies }\end{array}$ & Total & $\begin{array}{c}\text { User } \\
\text { Accuracy }\end{array}$ \\
\hline Barren Land & 19 & 1 & 0 & 0 & 0 & 20 & 95 \\
\hline Built Up Land & 1 & 38 & 0 & 1 & 0 & 40 & 95 \\
\hline Mining Land & 0 & 0 & 5 & 0 & 0 & 5 & 100 \\
\hline Vegetation & 0 & 2 & 0 & 78 & 0 & 80 & 97.5 \\
\hline Waterbodies & 0 & 0 & 0 & 0 & 5 & 5 & 100 \\
\hline Total & 20 & 41 & 5 & 79 & 5 & 150 & \\
\hline Producer Accuracy & 95 & 92.68 & 100 & 98.73 & 100 & & \\
\hline
\end{tabular}

The error matrix provides two kinds of accuracy namely, producer accuracy and user accuracy. The producer accuracy pertained to waterbody on a ground was correctly classified on the satellite image. The user accuracy of the classified waterbody on the satellite image was found correctly matches with ground condition. It was also clear that, the user and producer accuracy of barren land was 95 and 95, built up land was 95 and 92.68, mining land was 100 and 100 , vegetation was 97.5 and 98.73 , water bodies were 100 and 100 respectively. The overall accuracy of classification was 96.66. According to Anderson (1976), the accuracy of interpretation for the classes required is about equal and minimum level of land use and land cover accuracy should be 85 per cent. The resulted classes and overall accuracy of the classified images were well within the accepted level of accuracy in the present study. Cohen's Kappa analysis was also used to understand the accuracy of classified imagery. It is one of the popular techniques to identify the accuracy of the classified image attempted by several researchers in the field of land use and land cover mapping (Reis, 2008; Kaul and Sopan, 2012; Rawat and Kumar, 2015; Tilahun and Teferie, 2015; Liping et al., 2018). Kappa analysis is performed using error matrix, it is a discrete multivariate calculation used for the determination of land use and land cover map accuracy. Kappa coefficient varies between 0 and 1 , wherein 0 is indicative of the lack of agreements exists between the variables used. Whereas 1 is indicative of the strong agreements present between the variables. The result of Kappa coefficient can be classified into five groups based on the agreements of variables used in the calculation. If the result of Kappa coefficient is $<0.2$, it is considered as having poor agreement. If the range is between 0.2 and 0.4 , it is considered as having fair agreement. If Kappa coefficient is fallen between 0.4 and 0.6 , it is considered to have moderate agreement. If the result is found between 0.6 and 0.8 , it is considered as having good agreement between the variables. If the Kappa coefficient between 0.8 and 1 , it is considered as having strong agreement. Equation 1 shows the formula for the computation of Kappa coefficient.

$$
\kappa=\frac{N \sum_{i=1}^{r} x_{i i}-\sum_{i=1}^{r}\left(x_{i+} \times x_{+i}\right)}{N^{2}-\sum_{i=1}^{r}\left(x_{i+} \times x_{+i}\right)}
$$

In above formula, ' $N$ ' indicates total number of sites in the matrix. ' $r$ ' indicates the number of rows in the matrix. ' $X_{i i}$ ' indicates the number in row ' $I$ '. ' $X+l$ ' indicates the total for row ' $I$ '. ' $X_{i}+$ ' indicates the total for column 'i' (Jensen, 1996). The Kappa result of land use and land cover classification of present study was '0.94' which is considered as having strong agreement type. The information obtained from the field visit was applied on the classified image and anomalies in the data were corrected. Further spatial extension of each classified classes was identified and mapped using GIS software.

\section{RESULTS AND DISCUSSION LULC Classification of 2000}

The LULC classification of study area for the year 2000 was carried out by adopting Supportive Vector Machine classification method using Landsat 5 Thematic mapper Landsat satellite image. Landsat TM image was used owing to its free availability and in the season, as Sentinel satellite was not launched by then. The result of land use and land cover was observed visually in the software and based on the field visit the errors in the result were corrected accordingly. Totally five classes were identified that were mapped as barren, built up, mining, vegetation 
and waterbody categories. The spatial extensions of each class were identified and shown in the Table 2, the spatial extension of identified classes was mapped and shown in the Figures 1 and 2.

Table 02: Land Use and Land Cover Classification - 2000

\begin{tabular}{|c|l|c|c|}
\hline$\#$ & Class Name & Area (Sq. hac.) & Area (\%) \\
\hline 1 & Vegetation & 232.06 & 51.34 \\
\hline 2 & Barren Land & 143.52 & 31.75 \\
\hline 3 & Built Up Land & 66.34 & 14.68 \\
\hline 4 & Mining Land & 7.47 & 1.65 \\
\hline 5 & Waterbodies & 2.57 & 0.57 \\
\hline \multicolumn{2}{|r|}{ Total } & 452 & 100.00 \\
\hline
\end{tabular}

Figure 01: Classified Image in the Year 2000



From the table 2 it was very clear that, during the year 2000 the larger area was covered by vegetation which is about 51.34 per cent (232.06 hac.) followed by barren land which of 31.75 per cent (143.52 hac.), built up land of about 14.68 per cent (66.34 hac.) and mining land of about 1.65 per cent ( 7.47 hac.), with the lesser area of waterbodies which is about 0.57 per cent (2.57 hac.).

Figure 02: Relative Occurrence of Classified Image in the Year 2000

Land Use and Land Cover Classification - 2000

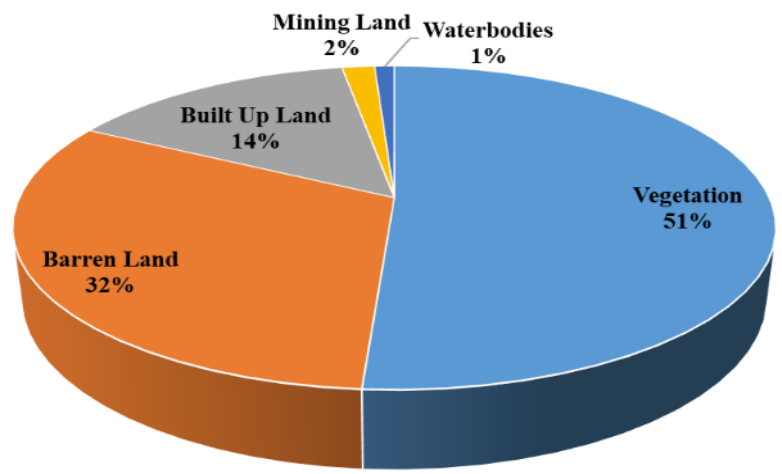




\section{LULC Classification of 2017}

The LULC of year 2017 was carried out by employing the Supportive Vector Machine classification method using Sentinel satellite image. By following the categories done for 2000 LULC classification, similar five classes were used in 2017 for classifying as barren, built up, mining, vegetation and waterbody (Table 3 ). The field information was appropriately used before finalizing the final classified image (Figures 3 and 4).

Table 03: Land Use and Land Cover Classification - 2017

\begin{tabular}{|r|l|c|c|}
\hline$\#$ & Class Name & Area (Sq. hac.) & Area (\%) \\
\hline 1 & Vegetation & 264.26 & 58.46 \\
\hline 2 & Barren Land & 90.33 & 19.98 \\
\hline 3 & Built Up Land & 87.12 & 19.27 \\
\hline 4 & Mining Land & 7.48 & 1.65 \\
\hline 5 & Waterbodies & 2.81 & 0.62 \\
\hline Total & 452 & 100.00 \\
\hline
\end{tabular}

From the Table 3 it was visible that, during the year 2017 the larger area was covered by vegetation which is approximately 58.46 per cent ( 264.26 hac.) followed by barren land of about 19.98 per cent (90.33 hac.), built up land of 19.27 per cent ( 87.12 hac.), mining land of about 1.65 per cent ( 7.48 hac.), and the waterbodies of about 0.62 per cent $(2.81$ hac.).

Figure 03: Classified Image in the Year 2017

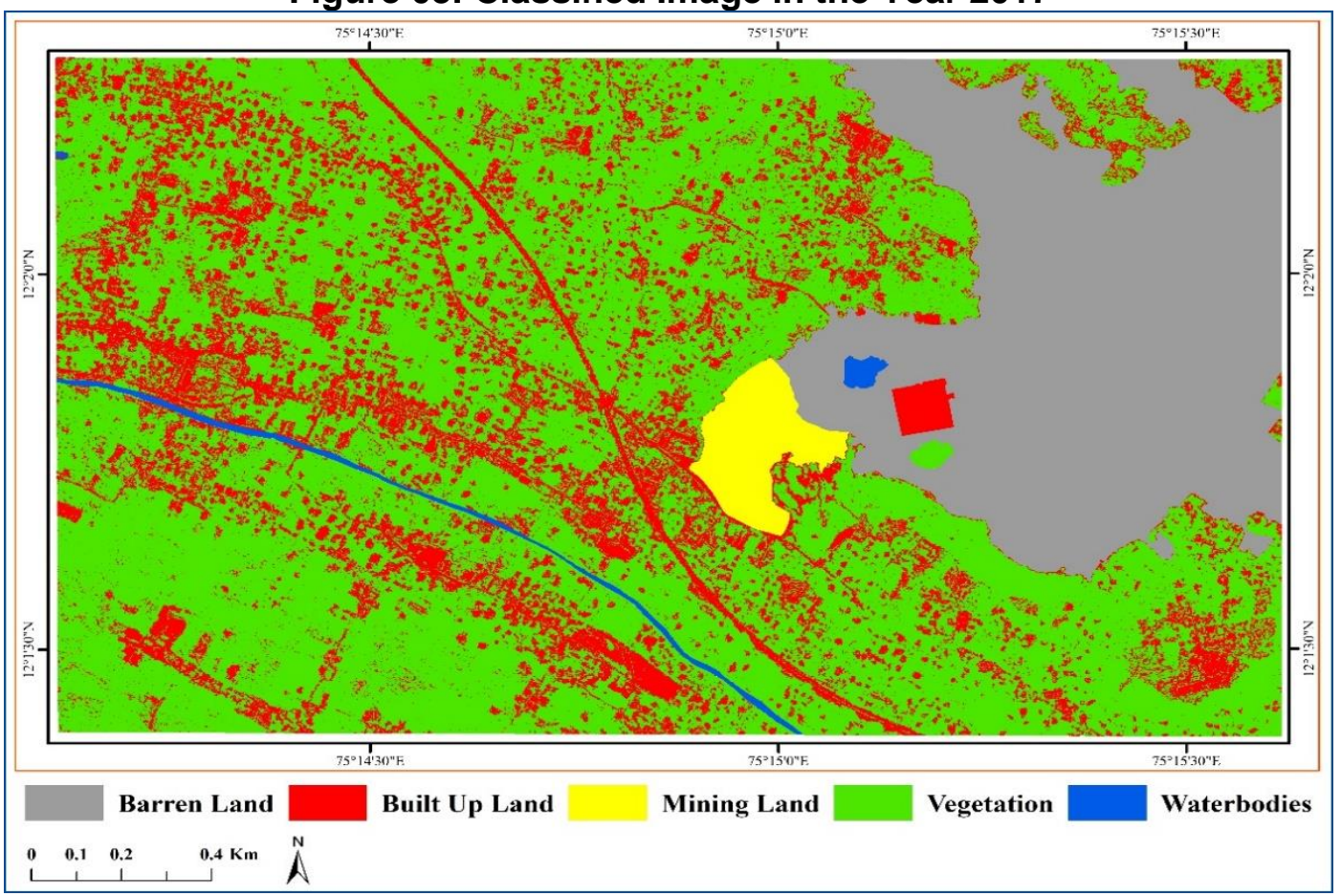

Figure 04: Relative Occurrence of Classified Image in the Year 2017

\section{Land Use and Land Cover Classification -}

\section{7}

\section{Waterbodies}

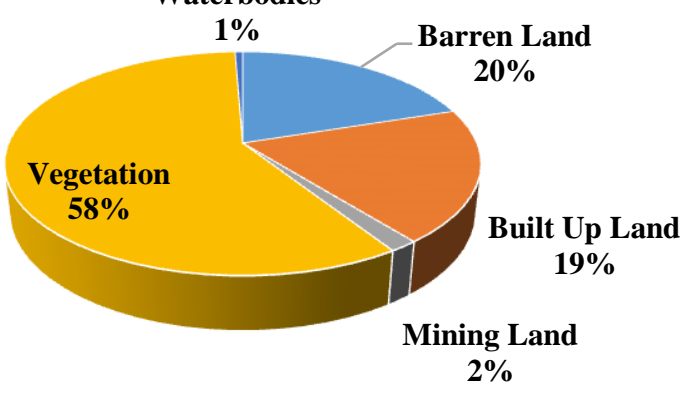




\section{LULC change between 2000 and 2017}

The result obtained through Landsat 5 satellite image for the year 2000 and the Sentinel satellite image for the year 2017 was compared to identify the temporal changes in the period of study. The spatial extension of each class in selected time periods were compared and shown in the Table 4. From the result it was clear that, 32.2 hac. of area covered by vegetation was increased, whereas 53.19 hac. of barren land was decreased. The area covered by built up was increased around 21 hac. and the area covered by mining land and waterbodies increased slightly as 0.01 hac. and 0.24 hec. respectively. Distinct increase in area of mining area was not visible much, as the mining processes took place with lots of excavation, without much increase in areal extent. The decrease barren land was largely gained by the increase in vegetation and built up land.

Table 04: Comparison of Land Use and Land Cover Classification Results

\begin{tabular}{|c|l|c|c|c|}
\hline$\#$ & Class Name & $\begin{array}{c}\text { LULC- 2000 Area } \\
\text { (Sq. hac.) }\end{array}$ & $\begin{array}{c}\text { LULC-2017 Area } \\
\text { (Sq. hac.) }\end{array}$ & $\begin{array}{c}\text { Changes Area } \\
\text { (Sq. hac.) }\end{array}$ \\
\hline 1 & Vegetation & 232.06 & 264.26 & 32.2 \\
\hline 2 & Barren Land & 143.52 & 90.33 & -53.19 \\
\hline 3 & Built Up Land & 66.34 & 87.12 & 20.78 \\
\hline 4 & Mining Land & 7.47 & 7.48 & 0.01 \\
\hline 5 & Waterbodies & 2.57 & 2.81 & 0.24 \\
\hline \multicolumn{2}{|l}{ Total } & 452 & 452 & \\
\hline
\end{tabular}

\section{Conclusion}

To understand the effects of geo-environmental impact on clay mining in Madayipara, land use and land cover pattern has been studied. The spatial distribution and temporal changes of different land use and land cover (LULC) of the study area was carried out. For this purpose, Landsat-5 Thematic Mapper and Sentinel-2 satellite imageries were used. The bands 1, 2, 3, 4, 5 and 7 of Landsat- 5 were used for generating the LULC for the year 2000 . Whereas, 2, 3, 4 and 8 bands of Sentinel-2 were used for the LULC classification of the year 2017. It was found that an increase of about 32.2 hac. of vegetation was recorded during this span of time in this study. Whereas, the barren land was decreased by 53.19 hac in this time. At the same time, the area covered by built up land have shown a considerable increase of about 21 hac. The area covered by mining land and water bodies were slightly increased as 0.01 hac. and 0.24 hac. respectively owing to mining as well anthropogenic activities. Distinct increase in area of mining area was not visible, as the excavation was mostly happened vertically in the same areal coverage. The mining activity had made significant changes in the land cover of the adjoining area, which had made significant impact on the environmental conditions of the area. Mined land should be reclaimed for future agricultural purposes or planting trees. Mined land should be reclaimed for future agricultural purposes or planting trees.

\section{References}

1. Abburu S and Golla S B (2015) Satellite Image Classification Methods and Techniques: A Review, International Journal of Computer Applications, Vol 199 (8), pp. $20-25$.

2. Abdel Rahman, S. (1996). Landsat Digital Data Processing of Land Use Land Cover Classification of East Nile Delta, Egypt, In : Escadafal Richard (ed.), Mulders M.A. (ed.), Thiombiano L. (ed.) Surveillance des sols dans l'environnement par télédétection et systèmes d'information géographiques $=$ Monitoring soils in the environment with remote sensing and GIS. Paris: ORSTOM.

3. Adam AHM, Elhag AMH, Abdelrahim SM (2013) Accuracy Assessment of Land Use \& Cover Classification (LU/LC) "Case study of Shomadi area - Renk County-Upper Nile State, South Sudan", International Journal of Scientific and Research Publications, Vol.3 (5).

4. Anderson J.R., Ernest E. Hardy, John T. Roach, and Richard E. Witmer (1976) A land use and land cover classif. System for use with remote sensor data, USGS Prof. Paper, Series No. 964, iii, 28.

5. Bahari NIS, Ahmad A and Aboobaider BM. (2014) Application of support vector machine for classification of multispectral data, 7th IGRSM International Remote Sensing \& GIS Conference and Exhibition, doi:10.1088/1755-1315/20/1/012038.

6. Borràs, J, Delegido, J, Pezzola, A., Pereira, M., Morassi, G., Camps-Valls, G. (2017) Clasificación de usos del suelo a partir de imágenes Sentinel-2, REVISTA DE Teledetección, Vol. 48, pp. 55-66.

7. Burian SJ, Brown MJ and McPherson TN (2002) Evaluation of land use/land cover datasets for urban watershed modeling, Water Science and Technology, Vol. 45 (9). 
8. Christoph Hütt, Wolfgang Koppe, Yuxin Miao and Georg Bareth (2016) Best Accuracy Land Use/Land Cover (LULC) Classification to Derive Crop Types Using Multitemporal, Multisensor, and Multi-Polarization SAR Satellite Images, Remote Sensing, MDPI, Vol. 8, 684 (15p).

9. Gordana Jakovljević (2018) Land Use / Land Cover Mapping from Sentinel 2 Data Using Machine Learning Algorithms, Research Paper, doi 10.7251/STP1813247J. pp. 247- 259.

10. Huang C, Davis LS and Townshend JRG (2002) An assessment of supportive vector machine for land cover classification, International Journal of Remote Sensing, Vol.23 (4).

11. Jeffrey A. Cardille and Jonathan A. Foley (2003) Agricultural land-use change in Brazilian Amazonia between 1980 and 1995: Evidence from integrated satellite and census data, Remote Sensing of Environment, Vil. 87, pp. 551-562.

12. Jensen J R (1996) Introductory Digital Image Processing: A Remote Sensing Perspective (Second Edition). Prentice Hall, Inc., Upper Saddle River, New Jersey, USA.

13. Kaul HA and Sopan I (2012). Land Use Land Cover Classification and Change Detection Using High Resolution Temporal Satellite Data, Journal of Environment, Vol. 01 (04).

14. Kim C (2016). Land use classification and land use change analysis using satellite images in Lombok Island, Indonesia, Forest Science and Technology, Vol. 12 (4), pp. 183-191.

15. Liping C, Yujun S and Saeed S (2018) Monitoring and predicting land use and land cover changes using remote sensing and GIS techniques-A case study of a hilly area, Jiangle, China, PLOS ONE, https://doi.org/10.1371/journal.pone.0200493.

16. Martins S, Bernardo N, Ogashawara I and Alcantara E (2016) Support Vector Machine algorithm optimal parameterization for change detection mapping in Funil Hydroelectric Reservoir (Rio de Janeiro State, Brazil), Model. Earth Syst. Environ, Vol.2 (138), pp. 1-10.

17. Mohammed-Aslam, M. A., Kondoh, A., P. Rafeekh Mohamed, \& Manoharan, A. N. (2010) Evaluating groundwater potential of a hard-rock aquifer using remote sensing and geophysics. Journal of Spatial Hydrology, 10(2).

18. Mohammed-Aslam, M. A., Rokhmatuloh, R. T., Salem, Z. E., \& Javzandulam, T. (2006). Linear Mixture Model applied to the land-cover classification in an alluvial plain using Landsat TM data. Journal of Environmental Informatics, 7(2), 95-101.

19. Nain $P$ and Kumar K (2016) Study for Accuracy Assessment of land use and land cover class. of New Delhi, North India, Intern. Jou. of Com. Sc, Trends and Technology, Vol.4 (3).

20. Nicola Clerici, Cesar Augusto Valbuena Calderón and Juan Manuel Posada (2017) Fusion of Sentinel-1A and Sentinel-2A data for land cover mapping: a case study in the lower Magdalena region, Colombia, Journal of Maps, Vol.13 (2), pp. 718-726.

21. Opeyemi Z A (2006). Change Detection in Land Use and Land Cover Using Remote Sensing Data and GIS (A case study of llorin and its environs in Kwara State.), A Master Degree Project submitted to University of Ibadan.

22. Paliwal M C and Katiyar S K (2015) Accuracy Assessment of Land Cover /Land Use Mapping Using Medium Resolution Satellite Imagery, International Journal of Scientific \& Engineering Research, Vol. 6 (7), pp. 1428- 1432.

23. Rao K V R, Kumar P R (2017) Land Cover Classification Using Sentinel-1 SAR Data, International Journal for Research in Applied Science \& Eng. Technology, Vol. 45 (98).

24. Rawat J S and Kumar M (2015). Monitoring land use/cover change using remote sensing and GIS techniques: A case study of Hawalbagh block, district Almora, Uttarakhand, India, Egyptian Journal of Remote Sensing and Space Science, Vol. 18 (1), and pp.77-84.

25. Reis S (2008). Analyzing Land Use/Land Cover Changes Using Remote Sensing and GIS in Rize, North-East Turkey, Sensors, Vol. 8, pp. 6188-6202.

26. Steinhausen M J, Wagner P D, Narasimhan B and Waske B (2018) Combining Sentinel-1 and Sentinel-2 data for improved land use and land cover mapping of monsoon regions, Int $\mathrm{J}$ Appl Earth Obs Geoinformation, Vol. 73, pp. 595-604.

27. Sukawattanavijit C and Chen J (2017) GA-SVM Algorithm for Improving Land-Cover Classification Using SAR and Optical Remote Sensing Data, IEEE Geoscience and Remote Sensing. 14(3).

28. Taati A, Sarmadian F, Mousavi A, Pour C T H and Shahir A H E (2014). Land Use Classification using Support Vector Machine and Maximum Likelihood Algorithms by Landsat 5 TM Images, Walailak Journal - Engineering and Physical Sciences, Vol. 12 (8).

29. Tilahun A and Teferie B (2015). Accuracy Assessment of Land Use Land Cover Classification using Google Earth, American Journal of Environmental Protection, Vol. 4 (4).

30. Upadhyay R, Singh A, Shrivastav P and Thakur S (2015) Land Use/Land Cover Classification and Accuracy Assessment Using Satellite Data - A Case Study of Bhind District, Madhya Pradesh, International Journal of Agriculture Sciences, Vol. 7 (1).

31. Ustuner M, Sanli FB and Dixon B (2015) Application of Support Vector Machines for Landuse Classification Using High-Resolution Rapid Eye Images: A Sensitivity Analysis, European Journal of Remote Sensing, Vol. 48 (1), pp. 403-422.

32. Zheng H, Du P, Chen J, Xia J, Li E, Xu Z, Li X and Yokoya N (2017) Performance Evaluation of Downscaling Sentinel-2 Imagery for Land Use and Land Cover Classification by Spectral-Spatial Features, Remote Sensing, Vol. 9, pp. 1-17, doi:10.3390/rs9121274. 